\title{
Remembering one of our own
}

\author{
Ami E. Iskandrian ${ }^{\mathrm{a}}$ \\ a Department of Radiology, The University of Alabama at Birmingham, Birmingham, AL
}

Received Feb 22, 2021; accepted Feb 22, 2021

doi: $10.1007 / \mathrm{s} 12350-021-02588-9$

We at JNC, the nuclear cardiology community, the cardiovascular community, the medical profession, and humanity at large mourn the loss of Henry Gewirtz, MD. $\mathrm{He}$ affected each one of us in his unique way and in the process advanced our understanding of the principles and applications of coronary physiology and cardiac imaging. A tribute by Ahmed Tawakol, MD, is forthcoming in the next print issue of the Journal. I'm also pleased to announce that Dr. Tawakol will serve as a
Guest Editor, a position held by the late Dr. Gewirtz for the past few years.

Ami E Iskandrian, MD, MASNC

Editor-in-Chief

Publisher's Note Springer Nature remains neutral with regard to jurisdictional claims in published maps and institutional affiliations.

Reprint requests: Ami E. Iskandrian, Department of Radiology, The University of Alabama at Birmingham, Birmingham, AL 35294; aiskand@uab.edu

J Nucl Cardiol 2021;28:385.

$1071-3581 / \$ 34.00$

Copyright (C) 2021 American Society of Nuclear Cardiology. 